\title{
CONTATO, IMPROVISAÇÃO E INTERAÇÃO: A DANÇA ENTRE MÃES E FILHOS COM DEFICIÊNCIA
}

\author{
Keyla Ferrari Lopes \\ Universidade Estadual de Campinas, São Paulo, Campinas, Brasil. \\ Paulo Ferreira Araújo \\ Universidade Estadual de Campinas, São Paulo, Campinas, Brasil.
}

\begin{abstract}
Resumo
Este estudo tem como objetivo refletir sobre os depoimentos de mães de crianças com deficiência que participaram de atividades práticas de dança contato improvisação juntamente com seus filhos. As atividades foram planejadas e desenvolvidas com um grupo de crianças e jovens com diferentes habilidades motoras e cognitivas, e a participação das mães era necessária. Foram utilizadas as contribuições de Bardin para a análise da entrevista aplicada ao grupo de oito mães que participaram dessa atividade. Observamos que a interação entre mãe e filho mediada pelo movimento corporal trouxe benefícios nos aspectos motores, emocionais e afetivos para ambas as partes. As mães e crianças deste estudo superaram limitações corporais e afetivas.
\end{abstract}

Palavras-chave: Dança. Deficiência. Movimento.

\section{Introdução}

A criança nasce, desenvolve-se, cresce conhecendo, explorando e vivenciando o mundo através do seu próprio corpo. É por meio da ação do corpo que ela reconhece, explora e interage no espaço em que vive.

De acordo com Garanhani (2002), na pequena infância, o corpo em movimento constitui a matriz básica da aprendizagem pelo fato de gestar as significações do aprender; ou seja, a criança transforma em símbolo aquilo que pode experimentar corporalmente, e seu pensamento se constrói, primeiramente, sob a forma de ação.

Assim, a criança necessita agir por meio de movimento corporal a fim de compreender e expressar os significados presentes no contexto histórico-cultural em que se encontra. Wallon (1979) ressalta que, na pequena infância, o ato mental se desenvolve no ato motor; ou seja, a criança pensa na ação. Isso faz com que o movimento do corpo ganhe um papel de destaque nas fases do desenvolvimento infantil. Wallon (1988) destaca também a importância dos movimentos expressivos, que têm uma função comunicativa intrínseca, estando usualmente associados a outros indivíduos ou sendo usados para uma estruturação do pensamento do próprio movimentador. Para o autor, a afetividade, por sua vez, seria a primeira forma de interação com o meio ambiente e a motivação primeira do movimento. À medida que o movimento proporciona experiências à criança, ela responde através de emoções, diferenciando a si mesma do ambiente.

A criança que possui uma condição de deficiência apresenta fatores limitantes no desenvolvimento global, no ato motor e na interação com o ambiente. Nesse sentido, Ferreira, et. al. (2010) dizem que qualquer deficiência física é uma condição que redimensiona os meios de interação com o ambiente. Segundo os mesmos autores (2010), a deficiência, 
interfere no desenvolvimento de quem a possui, na sua aprendizagem, nas suas relações familiares e na organização dinâmica de sua personalidade. É, assim, um elemento constitutivo dos aspectos estruturais e funcionais de sua pessoa total.

Todavia, a influência da deficiência está relacionada a inúmeros fatores: ao tipo de deficiência, à sua intensidade, à sua extensão, à época de sua incidência e, principalmente, às oportunidades de desenvolvimento e ajustamento que foram oferecidas ou negadas às pessoas portadoras.

Na concepção de Fux (1983), todos têm necessidade de "desfrutar do movimento de acordo com suas potencialidades, progredir nele até se mover em liberdade, com suas próprias expressões. Então o movimento terá papel de vitalizar, no lugar de anular". Nesse sentido, a criança com uma condição de deficiência necessita de oportunidades que favoreçam a expressão e manipulação do seu corpo para poder melhor percebê-lo e interagir com o seu meio.

A dança é vista como uma forma de expressão artística que contribui para a formação intelectual, físico e sócio-emocional do ser humano como um todo. Nunes (2003) diz que dançar é aprofundar o conhecimento da vida do corpo retratado por experiências sensoriais, motoras e emotivas. Para Venâncio \& Costa (2005), a dança existe porque o corpo a torna possível, ao mesmo tempo em que existe o corpo do outro com quem dançar ou apreciá-lo dançando.

Lopes (2011, p.76) diz que "ninguém melhor do que a mãe é capaz de conhecer e explorar as potencialidades do corpo de seu filho, visto que, desde a vida intrauterina, essa criança foi carregada e embalada pela mãe, ambas com os seus ritmos e movimentos". Se a criança possui uma condição de deficiência, na maioria dos casos, as mães se encontram em situações fundamentais como carregar, manipular, posicionar, conduzir e muitas outras para auxiliar seus filhos nas atividades cotidianas. Sendo assim, as situações permitem na prática que essas mães desenvolvam um conhecimento sensível a respeito das potencialidades de movimento, equilíbrio, postura e peso do corpo do seu filho. Entretanto, não é comum para elas fazer uso desse conhecimento para realização de atividades corporais e expressivas em conjunto.

Partindo desse contexto, vemos a necessidade de incentivar as mães e de facilitar a sua participação nas atividades corporais e nas aulas de dança em conjunto com seus filhos, a fim de auxiliá-los no desenvolvimento e interação com o ambiente.

Entre as diversas metodologias existentes de atuação prática com a dança e com o movimento, destaca-se, para os fins deste trabalho, a metodologia do contato e improvisação. Essa prática de dança foi criada e desenvolvida nos anos 70 nos Estados Unidos pelo bailarino Steve Paxton. Ela se fundamenta em uma forma de dança espontânea, sensorial e física em que duas ou mais pessoas brincam com o movimento, o toque e o apoio como base para um diálogo expressivo corporal improvisado.

Este artigo busca refletir sobre os depoimentos de mães que participaram de atividades práticas envolvendo movimento corporal, dança contato improvisação realizada com um grupo composto por mães e seus filhos (crianças com diferentes condições de deficiência motora e cognitiva). Este estudo reflete também sobre a díade apresentada na relação com o contato corporal e movimento em pares, assim como na vivência com o grupo composto de outras mães e seus filhos, além dos possíveis benefícios dessa atividade, tendo a professora como mediadora.

Para melhor compreendermos a procura das mães pela atividade da dança e a sua motivação, realizamos uma síntese do caminho normalmente percorrido pelas participantes 
deste estudo na busca de atividades e terapias que melhorassem a qualidade de vida dos seus filhos.

1. As mães que participaram deste estudo procuraram diversos profissionais e instituições para auxiliar na reabilitação de seus filhos que possuíam alguma condição de deficiência diagnosticada. Este processo de busca pela reabilitação da criança foi composto por trocas de instituições, clínicas e profissionais de reabilitação até que foi feita uma escolha, levando em consideração a singularidade de contextos e histórias pessoais de cada família.

2. Após esse primeiro estágio, no momento em que se definiu a escolha dos profissionais, estabeleceu-se, também, uma relação de confiança entre mãe, criança, instituição e profissional terapeuta.

3. Em uma terceira fase, percebeu-se que as mães buscaram atividades complementares que proporcionassem a seus filhos momentos de expressão, prazer e lazer, além de melhor qualidade de vida. Nessa fase, houve o encontro com a atividade da dança e a aproximação com o profissional responsável pela atividade. Ao complementar a perspectiva da terceira fase, Araújo (2010, p.28) diz que a estabilização de problemas imediatos ou secundários decorrentes da condição de deficiência possibilita novas tentativas, que normalmente acontecem no campo social e no esporte, emergindo em uma busca de ampliação de participação da pessoa com deficiência na vida como um todo.

4. Ao iniciar seus filhos na atividade e perceber o seu prazer e bem-estar, as mães começaram a se envolver nas atividades. Nessa fase houve motivação para uma maior aproximação entre mãe e filho, que se estabeleceu pela confiança no profissional e na atividade, o que possibilitou resultados positivos visíveis na vida da criança.

Faz-se necessário considerar que existiu, por parte das mães envolvidas neste estudo, uma afinidade com a proposta. Seus momentos e desejos foram respeitados e isso facilitou a sua participação.

Formou-se, então, uma dupla de dançarinos exploradores do movimento, composta por mãe e filho com deficiência. Essa formação foi mediada pelo profissional da dança, que propôs atividades e que interveio quando necessário.

\section{Métodos}

Este estudo caracterizou-se por uma pesquisa qualitativa que consistiu na realização de entrevistas com oito mães de crianças e jovens, em faixa etária entre nove e dezessete anos, com deficiência física motora e cognitiva, sendo sete crianças e jovens do sexo feminino e uma criança do sexo masculino.

Os dados foram coletados através de entrevistas realizadas por meio de contato direto da pesquisadora com as mães do grupo de dança que praticavam atividade duas vezes por semana juntamente com seus filhos. As entrevistas partiram da seguinte questão aberta: "Você acha que a sua participação nas aulas de dança trouxe benefícios para seu(sua) filho(a)? Se a resposta for sim, quais são os benefícios que você identificou?" 
As atividades duravam cerca de uma hora. Elas eram realizadas com ênfase na prática de movimento corporal e dança, e na técnica adaptada do contato e improvisação. A técnica criada por Steve Paxton em 1970 consiste num trabalho em dupla, ou em grupo, em que o peso e contra-peso são os elementos chaves para o movimento acontecer, de forma improvisada, mas consciente, na relação entre corpos. O contato-improvisação trabalha a sustentação física, trazendo para o corpo um conhecimento próprio sobre seus limites na relação com o outro, uma vez que funciona como um jogo silencioso (físico) de pergunta e resposta, além de ser potencialmente uma ferramenta de auto-conhecimento, utiliza pontos de apoio, flexibilidade e criatividade, podendo gerar desenhos de movimento muito interessantes em duplas.

Neste sentido as atividades eram executadas em duplas de mãe e filho, com os movimentos espontâneos e geralmente eram finalizadas com brincadeiras dirigidas.

As entrevistas foram gravadas e transcritas na íntegra, recebendo aprovação do comitê de ética, com parecer de número 910/2009. As entrevistas foram aplicadas no Centro de Dança Integrado, instituição situada na cidade de Campinas, no estado de São Paulo, local onde as mães e seus filhos desenvolviam as atividades de dança todas as semanas.

Para a realização de uma análise detalhada dos dados coletados nas entrevistas, utilizaram-se as contribuições de Bardin (1977) sobre a análise de conteúdo das narrativas, enquanto técnica científica e sistematizada, procurando um alinhamento do referencial teórico com a fonte oral. A análise de conteúdo (Bardin, 1977) é entendida como um conjunto de técnicas de exploração de documentos e discursos e visa à identificação de conceitos e temas abordados em determinados documentos e textos.

A escolha dessa metodologia permitiu associar os dados coletados por meio da pesquisa bibliográfica aos dados coletados através da pesquisa de campo. As convergências e/ou divergências entre ambas, quando existentes, levaram a uma melhor e mais isenta interpretação dos depoimentos.

\section{Resultados}

Com o propósito de atender os objetivos deste estudo, apresentamos a sequência dos dados coletados nas entrevistas das mães praticantes da atividade dança contato improvisação com seus filhos.

As oito entrevistadas foram identificadas como "M" e numeradas de acordo com a ordem em que as entrevistas foram realizadas. Relacionamos os números de identificação dos filhos de acordo com a sequência das entrevistas de suas mães e os identificamos como crianças $\mathrm{C} 1, \mathrm{C} 2, \mathrm{C} 3$ etc.

Na tabela 1, estão reunidas as informações que caracterizam o perfil das oito mães entrevistadas neste estudo:

$\begin{array}{cccc}\text { Mãe } & \text { Idade } & \text { Ocupação } & \text { Tempo de atividade com o filho } \\ \text { M1 } & 35 \text { anos } & \text { Dona de casa } & 2 \text { anos } \\ \text { M2 } & 44 \text { anos } & \text { Dona de casa } & 4 \text { anos } \\ \text { M3 } & 42 \text { anos } & \text { Autônoma em ven- } & 4 \text { anos }\end{array}$




$\begin{array}{cccc} & & \text { das } \\ \text { M4 } & 37 \text { anos } & \text { Dona de casa } & 6 \text { meses } \\ \text { M5 } & 39 \text { anos } & \text { Fonoaudióloga } & 2 \text { anos } \\ \text { M6 } & 32 \text { anos } & \text { Dona de casa } & 1 \text { ano } \\ \text { M7 } & 46 \text { anos } & \text { Dona de casa } & 3 \text { anos } \\ \text { M8 } & 36 \text { anos } & \text { Autônoma } & 10 \text { meses }\end{array}$

$\mathrm{Na}$ Tabela 2, estão reunidas as informações que caracterizam o perfil das oito crianças e jovens, de fundamental importância para o melhor entendimento da análise efetuada a partir dos resultados obtidos nas entrevistas das mães.

$\begin{array}{ccccc}\begin{array}{c}\text { Criança / } \\ \text { Jovem }\end{array} & \text { Idade } & \text { Sexo } & \text { Deficiência } & \begin{array}{c}\text { Tempo de atividade } \\ \text { com a mãe }\end{array} \\ \text { C1 } & 10 \text { anos } & \text { Fem. } & \text { Síndrome de Down } & 2 \text { anos } \\ \text { C2 } & 17 \text { anos } & \text { Fem. } & \text { Síndrome de Down } & 4 \text { anos } \\ \text { C3 } & 12 \text { anos } & \text { Fem. } & \text { Síndrome de Down } & 4 \text { anos } \\ \text { C4 } & 12 \text { anos } & \text { Fem. } & \begin{array}{c}\text { Paralisia cerebral tetraplegia } \\ \text { usuários de cadeiras de rodas }\end{array} & 6 \text { meses } \\ \text { C5 } & 15 \text { anos } & \text { Fem. } & \begin{array}{c}\text { Deficiência mental e motora não } \\ \text { usuária de cadeira de rodas }\end{array} & 2 \text { anos } \\ \text { C6 } & 9 \text { anos } & \text { Fem. } & \begin{array}{c}\text { Paralisia cerebral tetraplegia } \\ \text { usuário de cadeiras de rodas }\end{array} & 1 \text { ano } \\ \text { C7 } & 10 \text { anos } & \text { Fem. } & \text { Síndrome de Down } & 3 \text { anos } \\ \text { C8 } & 12 \text { anos } & \text { Masc. } & \text { Síndrome de Down } & 10 \text { meses }\end{array}$

Observa-se, nesse grupo, que as duplas de mãe e filho não iniciaram a atividade ao mesmo tempo. Há uma variação de tempo do início da atividade prática, com o mínimo de seis meses e máximo de quatro anos.

Categorias Identificadas nos Discursos das Mães

Pergunta: "Você acha que a sua participação nas aulas de dança trouxe benefícios para seu(sua) filho(a)? Se a resposta for sim, quais são os benefícios que você identificou?”

Partindo dos indicadores retirados dos discursos das mães, identificamos três categorias principais e cinco subcategorias para cada uma das categorias principais, conforme mostra a Tabela 3: 


$\begin{array}{ccc}\begin{array}{c}\text { Benefícios psicológi- } \\ \text { cos }\end{array} & \begin{array}{c}\text { Benefícios físicos moto- } \\ \text { res }\end{array} & \begin{array}{c}\text { Benefícios para o } \\ \text { relacionamento mãe-filho }\end{array} \\ \text { Autoestima } & \text { Postura } & \text { Carinho } \\ \text { Concentração } & \text { Coordenação Motora } & \text { Melhora geral } \\ \text { Disciplina } & \text { Equilíbrio } & \text { Prazer } \\ \text { Autonomia } & \text { Criatividade } & \begin{array}{c}\text { Compartilhamento de momentos; } \\ \text { Descoberta corporal de mãe e } \\ \end{array} \\ & \text { filho(a) }\end{array}$

\section{Discussão}

A proposta para a discussão dos dados registrados no decorrer do nosso estudo é apresentada observando o referencial teórico, os discursos das mães e as categorias e subcategorias identificados nas respostas obtidas nas entrevistas, segundo Bardin (1977).

A primeira categoria identificada relaciona-se aos benefícios psicológicos. Consideramos que essa categoria encontra-se intimamente ligada à seguinte, que se refere ao relacionamento entre mãe e filho.

Encontramos nos discursos das mães M2, M7 e M8 uma percepção de melhoria na autoestima, concentração, disciplina e autonomia de seus filhos.

Mãe M2:

"Eu acho que sim. A [C2] sempre gostou de dançar. Ela tem talento, mas descobriu através das aulas de dança. Agora ela dança comigo e gosta também de dançar sozinha com as amigas nos espetáculos. As pessoas elogiam muito. Ela está mais vaidosa e também mais concentrada para fazer as coisas".

Mãe M7:

"Dançar é um sonho, um sonho de infância que eu estou retomando agora com a minha filha. A [C7] sempre foi gordinha e pesada, mas ela adquiriu uma leveza e está tão bonita. Ela agora tem mais graça, gosta de se arrumar para vir para a aula, levanta cedo e sabe o dia certo da dança. Eu, que sempre gostei de dançar, para mim não foi nenhum sacrifício. Queria é poder vir mais vezes na semana, mas não dá . Eu acho que a [C7] dorme melhor no dia da dança e acho que vai acabar emagrecendo, porque ela fica dançando em casa e agora quer que todo mundo dance, o pai, a irmã. É um barato, é alegria da casa".

Mãe M8:

"Eu acredito muito nos benefícios que a dança traz. Eu nunca tive estes preconceitos de que menino não pode dançar. Meu filho já tem poucas oportunidades e, então, por que eu vou privá-lo de fazer as coisas que ele 
gosta? Nós sempre tivemos uma relação difícil, até por conta da história lá de casa, separação e todo o resto. No começo, você lembra que o [C8] não aceitava que eu assistisse ele dançando. Eu achava que nós dois nunca fossemos dar um bom par, pois ele me via e parava logo de dançar. Eu saía e ele fazia. $\mathrm{O}$ dia em que eu comecei a dançar na mesma aula que ele, me viu dançando, mas com outra amiguinha e não com ele. Pareceu que ele ficou com um certo ciúme quando chegou em casa. Ele quis fazer os passos da aula comigo e na aula seguinte nós já começamos a dançar juntos. A dança me aproximou mais do meu filho, nossa relação melhorou em casa. Ele está mais feliz, mais obediente. Ele também está se mostrando bem criativo, com mais autonomia, de atitude mesmo e é isto".

Estudos como os de Harter (1993) apud Simão (2005) Weber, Stasiack e Brandenburg (2003) constataram que os pais são extremamente importantes na valorização e no apoio às atividades que as crianças realizam. Ao mostrarem entusiasmo e interesse pela vida dos seus filhos, os pais expressam o amor e respeito que sentem por eles, contribuindo para o desenvolvimento da autoestima.

No caso específico das mães, elas já possuem um vínculo afetivo e uma relação corporal direta com seus filhos desde a vida intrauterina, seguida de uma relação maternoinfantil que, de alguma maneira, produz um diálogo que constitui um mundo exclu sivo para o bebê, com uma dinâmica e um clima emocional específicos. Esse fator é importante para tornar a criança capaz de construir gradualmente uma imagem coerente do seu mundo (Spitz, 1996, p.32), independentemente de essa criança ter ou não uma condição de deficiência.

Sendo assim, as mães que participaram dessa atividade com seus filhos, partilharam momentos de trocas afetivas, olhares, carinhos, cumplicidade e incentivo, ainda que esses momentos apresentassem característica únicas e singulares para cada díade mãe-filho e com significados subjetivos. Consideramos neste estudo que a melhora na autoestima está relacionada a uma interação corporal de alta qualidade entre mãe e filho.

Alexander (1998) diz que a questão do "tato" e do "contato", considerando a pele como órgão, ensina-nos que o tato da pele proporciona informações sobre o mundo externo, dando-nos conhecimentos essenciais sobre nós mesmo, ao mesmo tempo em que afirma "tudo o que tocamos também nos toca".

Observamos no discurso da mãe M7 que ela realizou, através da atividade com sua filha, o seu desejo pessoal de dançar, o que é um fator motivacional para o bom andamento da atividade e para a aceitação da atividade por parte da filha, que percebeu o prazer da mãe em dançar com ela.

No caso da mãe M8, ficou evidente que há certo preconceito da sociedade em relação aos meninos que fazem dança. No entanto, ela considerou importante não privar seu filho da atividade que poderia beneficiá-lo, levando em conta as limitações que normalmente são impostas pela sua condição de deficiência.

O contato através da dança proporcionou a descoberta das capacidades e limites, além de um aumento significativo da autonomia e autoestima, evidenciando o "empoderamento" dessas crianças e jovens. Isso fica evidente no autocuidado com a aparência ao vestir as roupas para a aula de dança, na disciplina com os horários da atividade e na autonomia em relação às atitudes e ao ato de dançar em espetáculos com outros pares e também sem a presença da mãe, conforme relatou a mãe M2.

Na categoria identificada como "Benefícios para o relacionamento mãe-filho", os discursos das mães indicam que o ato de dançar com o filho(a) trouxe benefícios para ambas 
as partes, melhorando seu relacionamento afetivo cotidiano, como mostra o discurso da Mãe M1 e M8:

Mãe M1:

"Com certeza, minha filha passou a ficar menos agitada, mais carinhosa comigo e também melhorou muito a postura. Na escola, a professora observou que ela está mais atenta nas aulas. Eu acho que a minha participação foi importante para ela. Hoje nós trocamos mais carinhos".

Mãe M8: "A dança me aproximou mais do meu filho. Nossa relação melhorou em casa e ele está mais feliz, mais obediente".

De acordo com Fonseca (1988), o movimento humano é construído em função de um objetivo. A partir de uma intenção como expressividade íntima, o movimento transforma-se em comportamento significante. Ele é a parte mais ampla e significativa do comportamento do ser humano.

Nesse sentido, a dança repleta de gestos e movimentos é uma linguagem de expressão, comunicação, emoção e intencionalidade, favorecendo um novo encontro através da aproximação e das relações estabelecidas entre os diferentes modos de contato entre mãe e filho e que pode ressignificar também os relacionamentos cotidianos.

De acordo com Liberman (2008, p.159), ao ser tocado, é possível encontrar outro corpo que o ajude a saber mais de si e a experimentar outros jeitos de ser, fazer, pensar e agir, importantes para o enfrentamento das mais diversas situações.

Venâncio \& Costa (2005) explicam que o corpo e o outro na dança traduzem uma nova modalidade de amizade com base na sensibilidade. Revela-se uma possibilidade de constituir uma comunidade dançante em que se reconheça a pluralidade e se vivenciem relações livres e não institucionalizadas; ou seja, relações construídas independentemente de sexo, raça, classe social e crença, entre outros.

Com relação à categoria identificada como "Benefícios físicos motores", encontramos nas respostas da mãe M3 o relato de uma melhora significativa na postura, coordenação motora e equilíbrio de sua filha após o início das atividades.

Mãe M3:

\footnotetext{
"Ela melhorou na coordenação motora, equilíbrio, postura. Ela sempre foi muito brava e agora faz as coisas com mais paciência. Eu adoro o momento de dançar com ela. Não é sempre que dá tempo, mas às vezes dançamos em casa e criamos coreografias com as músicas que ela mais gosta".
}

Sobre a questão postural da criança e do jovem, Santos et. al. (2009) dizem que a má postura é uma das dificuldades da atualidade e que uma das causas desse problema é a não prevenção de maus hábitos posturais na infância. Segundo as autoras, a prática regular da dança é indicada para crianças e tem ação presente e preventiva na melhor qualidade de vida e postura dos praticantes.

Em relação à coordenação motora e ao equilíbrio, buscamos a definição de Gallardo (2000, p.31), que define a coordenação motora como sendo "a atuação conjunta do sistema nervoso central e da musculatura esquelética, na execução de um movimento". A coordenação é a direção significativa do movimento, a concretização de uma intenção ou o encadeamento significativo da conduta. 
Segundo Nascimento, Santos \& Santos (2007, p.2), “A dança favorece, também, a execução dos mais variados movimentos, possibilitando descobertas do próprio corpo, possibilidades e limites do mesmo, além da melhora da coordenação motora, aspecto importante para o desenvolvimento corporal posterior".

Nesse sentido, Alves, Boeno \& Dantas (1999, p.99) acreditam que "a dança é uma atividade que contribui para a melhoria das capacidades motoras afetivas e relacionais de crianças e jovens, ao mesmo tempo em que amplia as possibilidades de assimilação e produção cultural".

Segundo Castro (2005), a prática da dança pelas crianças com deficiência e pelos portadores de síndrome de down os beneficia pelos aspectos lúdicos que o movimento, a música ou sons proporcionam, dando oportunidade para a facilitação do movimento, da reabilitação ou reeducação do gesto.

No contexto lúdico da dança, encontramos também no discurso da mãe M7 ênfase na leveza adquirida pela criança ao movimentar seu corpo. Consideramos que essa leveza foi facilitada pelo estímulo musical utilizado durante as atividades, que muitas vezes são realizadas com músicas clássicas suaves, além de todo o contexto que envolve a dança como arte expressiva e sensível.

A criatividade aparece expressa no discurso da mãe da M8. A dança, especialmente na atividade de contato e improvisação, facilita a espontaneidade e a criatividade, o que, segundo Fux (1983), pode aumentar o repertório de comportamentos da criança quando estimulada a movimentar-se livremente.

Quando analisamos os discursos das mães que participaram da atividade, percebemos que houve uma reciprocidade na troca de afetos e maior aceitação dos filhos em relação às suas mães. Existiu também um compartilhamento de momentos únicos que tiveram significados para todas as partes envolvidas, pois houve um partilhar de histórias de vidas e saberes por parte das mães que se encontraram com objetivos similares e se descobriram no movimento artístico, como mostra o discurso da mãe M6:

“(...) Conviver com as outras mães, brincar, conversar e saber que nós não estamos sozinhas é uma terapia para mim. Eu nunca me imaginei dançando. Sempre fui dura. Comecei porque vi as outras mães dançando e pensei que, se elas podem, eu também posso. Fiz isto também pela minha filha, mas hoje eu penso que foi por mim. Fiz por mim também, porque, através dela, eu me descobri e quero continuar sempre dançando com ela".

As atividades lúdicas e coletivas como a dança contato improvisação facilitam os relacionamentos interpessoais entre o grupo, o desenvolvimento da autoestima e da autoconfiança tanto das mães quanto dos filhos. (FALSARELLA; AMORIM 2008).

De acordo com Lopes (2011), nasce uma comunicação silenciosa entre os dois corpos, com diferentes experiências emocionais, motoras e sensoriais. Há uma identidade na dança construída através do sentir e da interação com outro dançarino, desenvolvendo a cumplicidade e complementação dos gestos e movimentos elaborados em parcerias.

Foi possível perceber que a dança, enquanto instrumento de expressão e autoafirmação, proporcionou a liberação das emoções e, além disso, abriu canais de comunicação. Nesse caso, isso ocorreu entre mães e filhos, melhorando o seu relacionamento interpessoal. 


\title{
Considerações Finais
}

Com base na análise dos depoimentos das mães que participaram da atividade dança contato improvisação com seus filhos, percebe-se que a dança, o movimento corporal e o contato físico agiram como instrumento de expressão, brincadeira e criatividade, abrindo canais de comunicação entre mães e filhos. Proporcionaram também momentos de prazer e cumplicidade, melhorando o relacionamento entre as mães e filhos, além do relacionamento interpessoal das mães com o próprio grupo.

Nota-se que a maioria das mães entrevistadas neste estudo são donas-de-casa ou profissionais autônomas, o que lhes permite maior disponibilidade de tempo para acompanhar as atividades de seus filhos e lhes facilita a participação nas aulas de dança.

As mães, que primeiramente procuram participar da atividade a fim de beneficiar ou auxiliar o desenvolvimento de seus filhos, também encontraram realização pessoal na atividade e no contato com o grupo, através das trocas de experiências com outras mães. Elas obtiveram resultados positivos, pois transcenderam limitações de movimento corporal, além de desfrutar da convivência e da troca de experiências com as colegas do grupo.

Para as crianças e jovens com deficiência, os benefícios dessa atividade se estenderam no âmbito motor e emocional, evidenciando o ganho na autoestima e autonomia de atitudes.

A prática com o movimento corporal facilitou o relacionamento entre mãe e filho na vida cotidiana e em contextos diferentes do artístico criativo. Ao mesmo tempo, esse contexto também se estendeu, possibilitando trocas e dinâmicas expressivas em determinadas situações ocorridas no espaço familiar.

Faz-se necessário, cada vez mais, incentivar o envolvimento das mães e/ou pais em participar de atividades corporais e expressivas com seus filhos, principalmente se estes possuem alguma limitação motora ou cognitiva.

Este estudo ainda nos leva a pensar na continuidade do tema, a fim de que possamos futuramente ouvir também as crianças e jovens refletindo seus pontos de vista, seus desempenhos em cena e nos espetáculos e a influência da interação da figura materna nesse contexto.

\section{CONTACT, IMPROVISATION AND INTERACTION: THE DANCE BETWEEN MOTHERS AND DISABLED CHILDREN}

\begin{abstract}
This study aims to reflect on the testimonies of mothers of disabled children who participated in practical activities of dance contact improvisation along with their children. The activities were planned and developed with a group of children and young people with different motor and cognitive skills, in which the participation of the mothers was required. Bardin's contributions were used to analyze the interview applied to the group of eight mothers who participated in this activity. We observed that the interaction between mother and son mediated by body movement brought benefits regarding motor, affective and emotional aspects for both parties. Mothers and children in this study exceeded bodily and emotional limitations.
\end{abstract}

Keywords: Dance. Disabled. Movement. 


\section{CONTACTO, IMPROVISACIÓN E INTERACCIÓN: LA DANZA ENTRE LAS MADRES Y LOS NIÑOS CON DISCAPACID}

\section{Resumen}

Este estudio tiene como objetivo reflexionar sobre los testimonios de las madres de niños con discapacidad que participaron en las actividades de práctica de baile de improvisación de contacto, junto con sus hijos. Las actividades fueron planificadas y desarrolladas con un grupo de niños y jóvenes con diferentes habilidades motoras y cognitivas, en el que se requiere la participación de las madres. Se utilizaron para analizar la entrevista Bardin contribuciones aplicado al grupo de ocho mujeres que participaron en esta actividad. Hemos observado que la interacción entre madre e hijo movimiento corporal mediada trajo beneficios en aspectos de motor, afectivo y emocional para ambas partes. Las madres y los niños en este estudio excedió las limitaciones corporales y emocionales.

Palabras clave: Danza, Movimiento. Discapacidad.

\section{Referências}

ALEXANDER, G. Eutonia; um caminho para a percepção corporal. 2a ed. S. Paulo: Martins Fontes, 1998.

ALVES, M.; BOENO, A.; DANTAS, M. Dança corpo e representações. Revista Conexões: educação, esporte, lazer, Campinas,v.1, n.2, p.97-107, jun/1999. Disponível em: <http://www3.mackenzie.br/editora/index.php/remef/article/viewFile/1621/1190>.

Acesso em: 29 Abril, 2011.

ARAÚJO, P. Handebol em cadeira de rodas: regras e treinamentos. São Paulo: Phorte, 2010.

BARDIN, L. Análise de conteúdo. Lisboa: Edições 70LDA, 1977.

CASTRO, E. M. Atividade Física Adaptada. Ribeirão Preto: Tecmedd, 2005. Disponível em: $\quad\langle$ http://www3.mackenzie.br/editora/index.php/remef/article/viewFile/1621/1190>, Acesso em:30 Abril, 2011.

FALSARELLA, A.P, AMORIM, D.B. A importância da dança no desenvolvimento psicomotor de crianças e adolescentes. Revista Conexões: (vol. 6), Campinas, 2008.

FERREIRA, L. Natação para crianças com deficiência física e seu desenvolvimento psicomotor. 2010. Disponível em: <http://www.efdeportes.com>, acesso em: 30 Abril, 2011.

FONSECA, V. Psicomotricidade. 2.ed. São Paulo: Martins Fontes, 1988.

FUX, M. Dança, experiência de vida. São Paulo: Summus Editorial, 1983

GALLARDO, J.S.P. Educação Física: contribuições à formação profissional. 3.ed. Ijuí: Unijuí, 2000. 
GARANHANI, M. C. A educação física na escolarização da pequena infância. Revista Pensar a prática. (Vol 5), Goiás, 2002.

LIBERMAN, F. Delicadas coreografias: instantâneos de uma terapia corporal. São Paulo: Summus, 2008.

LOPES, K. Encontros com a dança: bailarinos muito especiais. Itu: República, 2002.

Identidade social e a autoconceito do dançarino em cadeira de rodas (2011), Dissertação (mestrado) - Faculdade de Educação Física, Universidade Estadual de Campinas, Campinas, 2011.

NASCIMENTO, F. M.; SANTOS, J. C.; SANTOS, E. V. Brincando de dançar: contribuições da dança na $2^{\mathrm{a}}$ infância. Pelotas: ESEF/UFP Pelotas, 2007 (Trabalho de Conclusão de Curso). Disponível em: <http://www3.mackenzie.br/editora/index.php/remef/article/viewFile/1621/1190>. Acesso em 01 Mai, 2011.

NUNES, C. Consciência do movimento a educação pelo corpo: dança, terapia e educação: caminhos Cruzados. In: CALAZANS, CASTILHO, GOMES. (org). Dança e Educação em Movimento. São Paulo: Cortez Editora, 2003.

SANTOS, C. I. et al . Ocorrência de desvios posturais em escolares do ensino público fundamental de Jaguariúna, São Paulo. In: Revista Paulista Pediatria, São Paulo, v. 27, n. 1, Mar. 2009 Disponível em: <http://www.scielo.br/scielo.php?script=sci_arttext\&pid=S010305822009000100012\&lng=en\&nrm=iso $>$. Acesso em 20 Out, 2012.

SIMÃO, R. I. P. A relação entre atividades extracurriculares e o desempenho acadêmico, motivação, autocontrole e auto-estima dos alunos. 2005. Monografia (Licenciatura em Psicologia) - Instituto Superior de Psicologia Aplicada, Lisboa, Portugal, 2005.

SPITZ, R.A. O primeiro ano de vida. 7ª ed. São Paulo: Martins Fontes, 1996.

VÊNANCIO, S. COSTA, E. Pensar e sentir o corpo na dança consigo e com o outro. In: DANTAS, E.H.M (org.). Pensando o corpo e o movimento. Rio de Janeiro: Shape, 2005.

WALLON H. As origens do pensamento na criança. São Paulo: Manole, 1988.

WEBER, L. N. D., STASIACK, G. R.; BRANDENBURG, O. J. Percepção da interação familiar E auto-estima de adolescentes. Aletheia, 17/18, p.95-10, 2003.

Recebido em: 07/08/2013

Revisado em: 07/03/2014

Aprovado em: 09/04/2014 
Endereço para correspondência:

keylafe@gmail.com

Keyla Ferrari Lopes

Universidade Estadual de Campinas, Faculdade de Educação.

Rua Érico Veríssimo, 701 - Cidade Universitária

Barão Geraldo

13083-851 - Campinas, SP - Brasil 